Figures in the Supporting information

for

\title{
Engineering thermally resistant catalytic particles for oxidative coupling of methane using spray-drying and incorporating SiC
}

Gontzal Lezcano, Vijay K. Velisoju, Shekhar R. Kulkarni, Adrian Ramirez, Pedro Castaño*

KAUST Catalysis Center (KCC), King Abdullah University of Science and Technology (KAUST), Thuwal, 23955-

6900, Saudi Arabia.e-mail:pedro.castano@kaust.edu.sa 


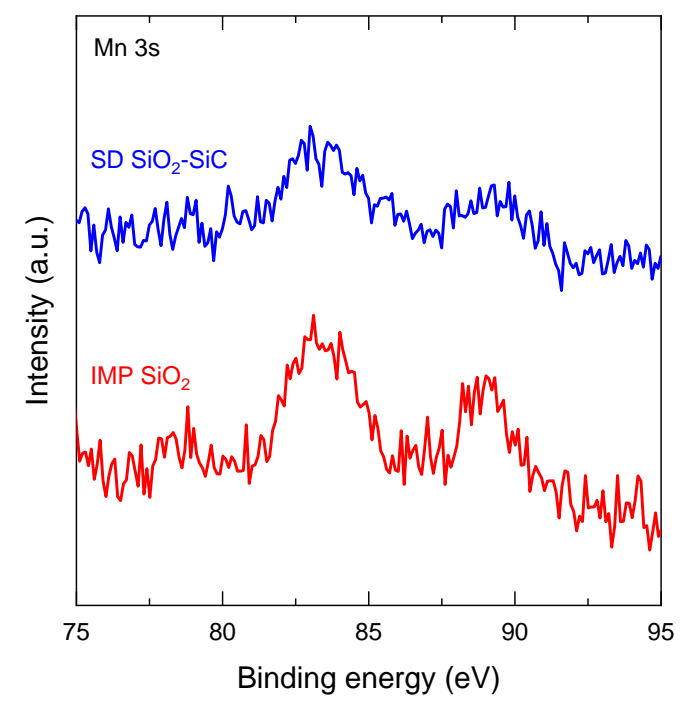

Figure S1. High-resolution Mn 3s XPS spectra of fresh $\mathrm{IMP} \mathrm{SiO}_{2}$ and $\mathrm{SD}-\mathrm{SiO}_{2}-\mathrm{SiC}$ catalysts.

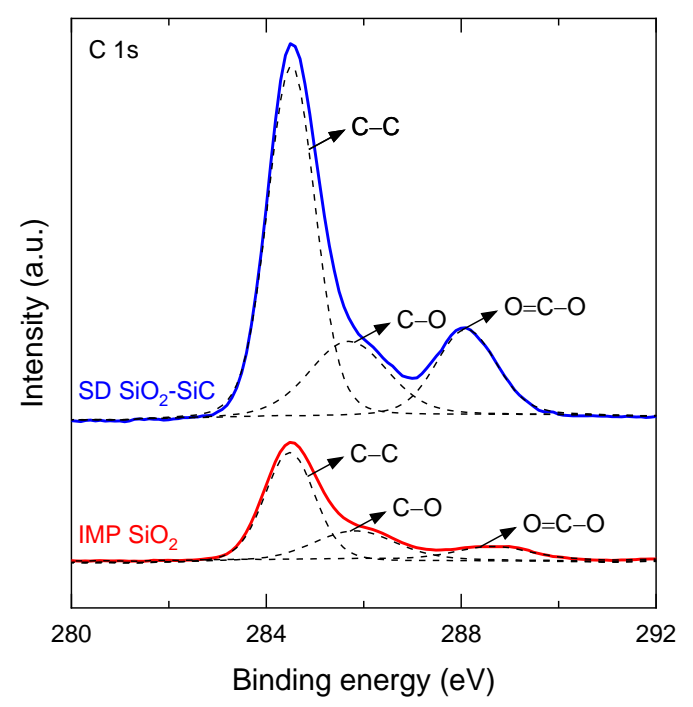

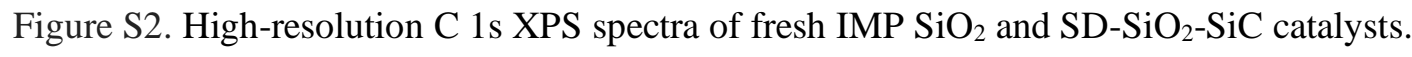



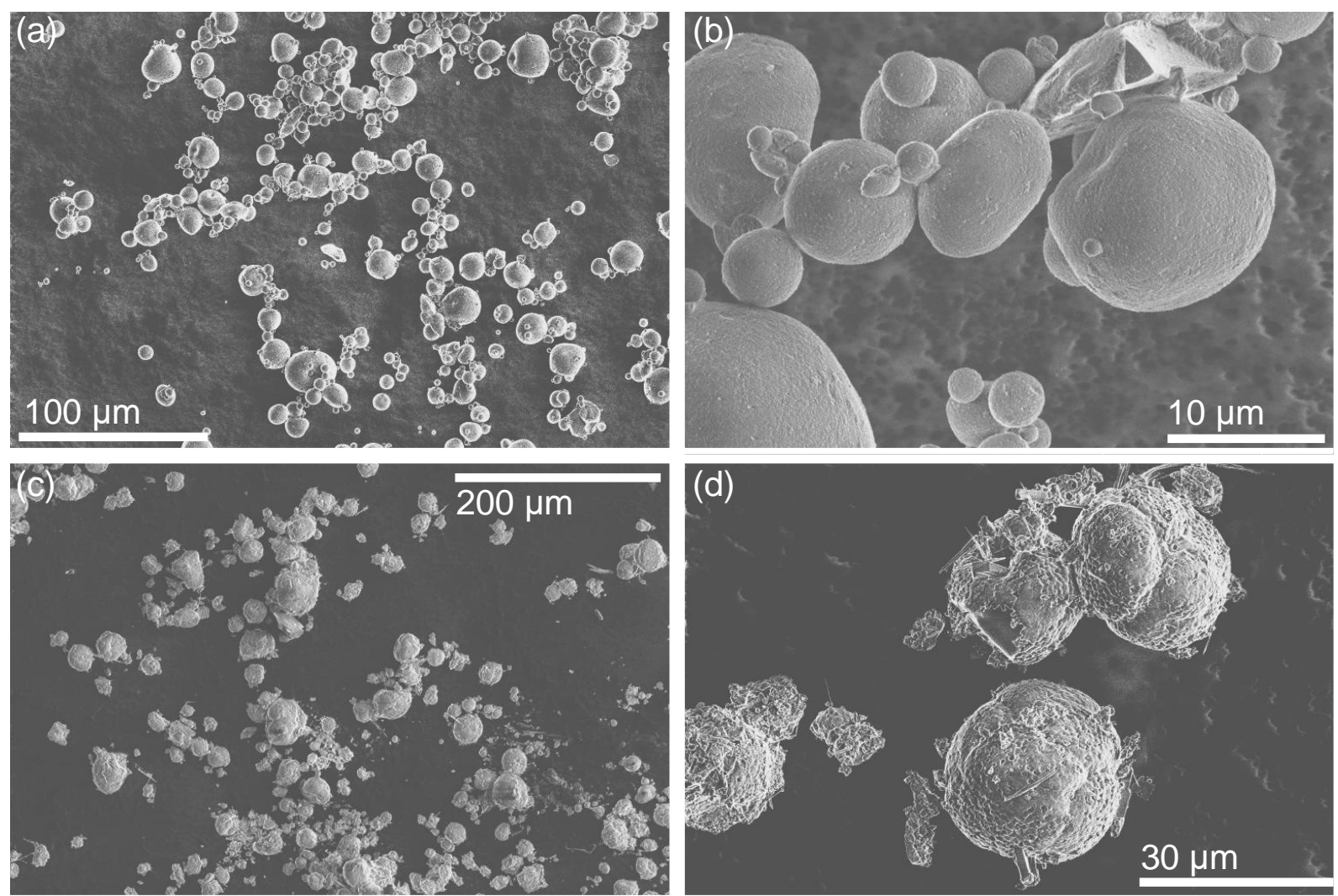

Figure S3. SEM images of the spray-dried $\mathrm{SiC}-\mathrm{SiO}_{2}$ samples before (a, b) and after (c, d) calcination.

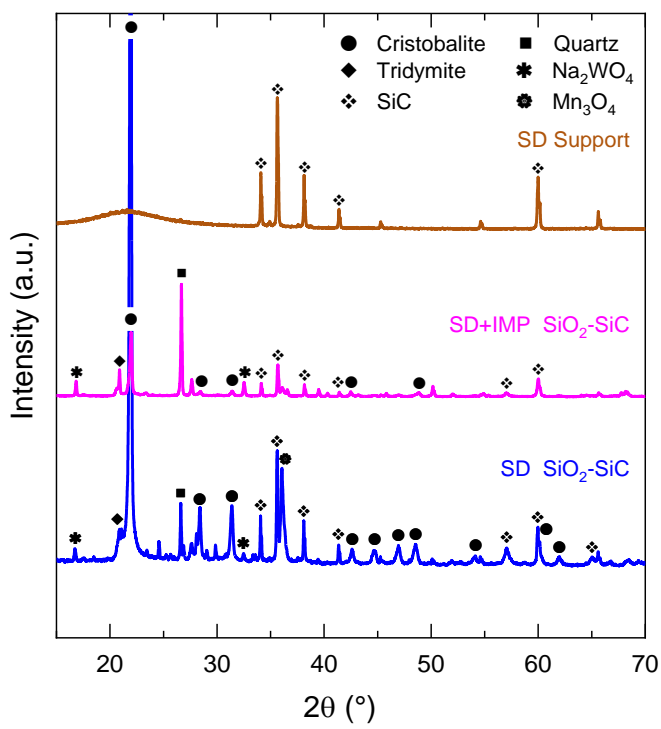

Figure S4. Powder XRD patterns of fresh SD Support, SD+IMP $\mathrm{SiO}_{2}-\mathrm{SiC}$ and $\mathrm{SD} \mathrm{SiO}_{2}-\mathrm{SiC}$ catalyst samples. 

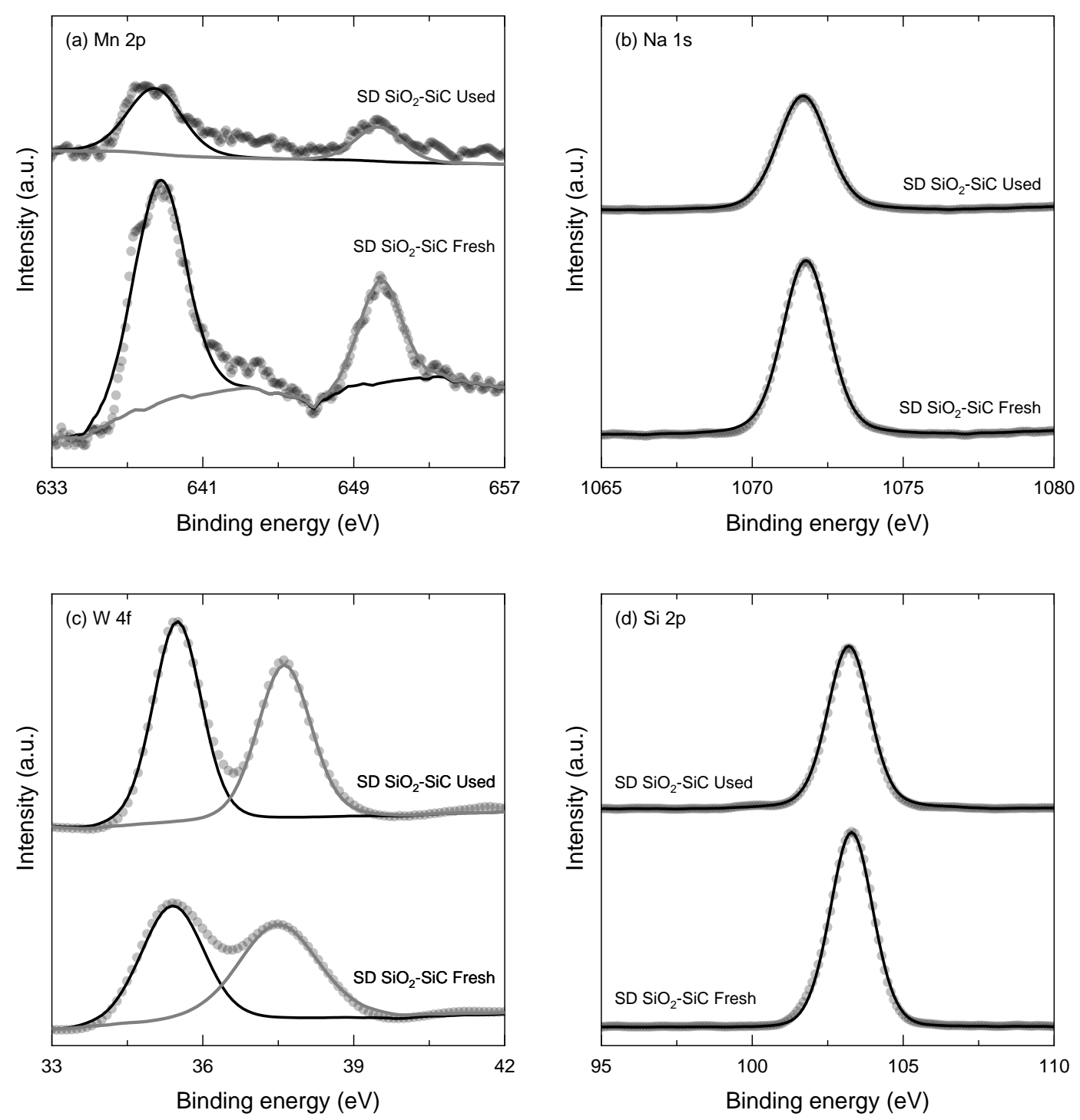

Figure S5. High resolution XPS spectra of the fresh and used spray-dried catalysts: (a) Mn 2p, (b) Na 1s, (c) W 4 f and (d) Si 2p. 


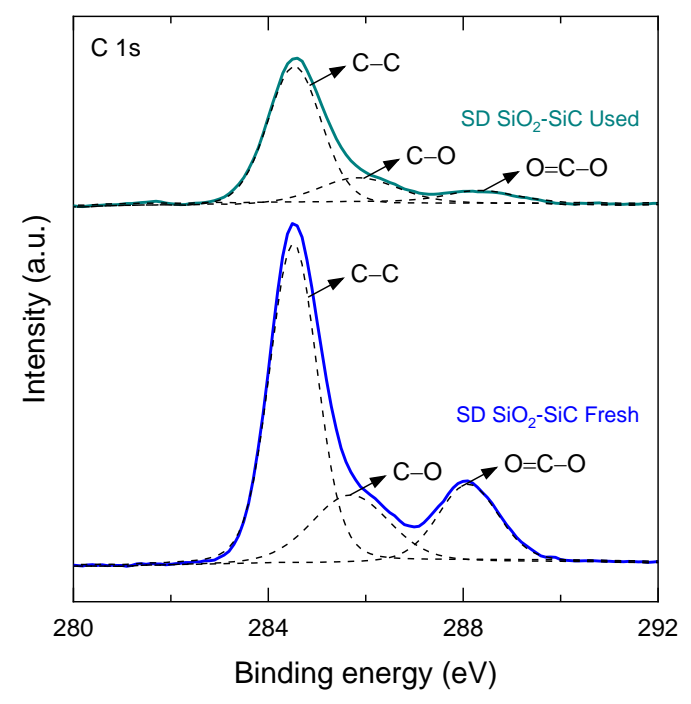

Figure S6. High-resolution C 1s XPS spectra of the fresh and used spray-dried catalysts. 